\title{
USING FIELD DATA TO VALIDATE SATELLITE MODELS OF ELK FORAGE IN THE UPPER YELLOWSTONE RIVER BASIN
}

\author{
ERICA GARROUTTE $\uparrow$ ANDREW HANSEN $\uparrow$ MONTANA STATE UNIVERSITY \\ BOZEMAN, MT
}

\section{$\uparrow \quad$ ABSTRACT}

Spatial and temporal variations in grassland phenology are thought to play a critical role in migration patterns of large herbivores in the Greater Yellowstone Ecosystem. Phenology, referring to the timing of green-up in this study, is directly related to biomass and forage quality. Migratory elk (Cervus elaphus), therefore, are believed to follow phenology across an elevation gradient during the growing season to maximize their access to high quality and quantity of forage. Concern that climate change and human land use alterations of phenology may impact the benefits of elk migration highlights the need for landscape-scale vegetation phenology monitoring. Satellite-derived Normalized Difference Vegetation Index (NDVI) shows potential as a remote sensing tool to predict landscape-level shifts in grassland phenology, but is limited by a lack of validation at varying scales, seasons, and in human land use areas. This study is focused on validating the accuracy of satellite-derived NDVI in estimating grassland phenology, biomass, and forage quality throughout the summer growing season within elk migratory ranges in the Upper Yellowstone River Basin. Results from this study will provide managers and researchers with information on the accuracy of NDVI as a tool for monitoring the effects of climate change and human land use on grassland dynamics relevant to migratory elk.

\section{INTRODUCTION}

Recent concern that climate change and human land use are altering vegetation phenology, growing season length, and productivity, highlights the importance of understanding the ecological consequences of altered vegetation dynamics (Inouye 2008). Vegetation phenology was identified by the Intergovernmental Panel on Climate Change report as "...perhaps the simplest process in which to track changes in the ecology of species in response to climate change" (Friedl et al. 1994). Research suggests that altered phenology may result in asynchrony between species, modified competition for resources, altered community interactions, shifts in growing season and productivity of vegetation, and shifts in trophic interactions (Chapin and Shaver 1996, Despain 1990, Inouye 2008).

Understanding the impacts of altered phenology on wildlife population dynamics is becoming especially important in the Greater Yellowstone Ecosystem (GYE), where recent research has suggested that shifts in vegetation phenology may have significant impacts on elk (Cervus elaphus) populations (Harris et al. 2009). A recent study by Middleton et. al. (2013) attributes a decline in pregnancy rates of a migratory Yellowstone elk herd, in part, to altered vegetation phenology. In addition to climate change, changes in human land use outside of protected areas have also been shown to alter the phenology of forage in elk migratory ranges north of the park (Piekielek 2012). These studies suggest that the effects of climate change and human land use on vegetation phenology may have significant impacts on migratory elk populations. However, before decision makers can be confident in these findings, more research is needed on the accuracy of the tools used to study vegetation dynamics.

Monitoring vegetation phenology was historically limited by the small-scale of traditional field research (Homer et al. 2004), but has been revitalized by advances in remote sensing. Remote 
sensing vegetation indices, such as Normalized Difference Vegetation Index (NDVI), have gained popularity in the study of phenology by offering large spatial and temporal scale information on vegetation dynamics relevant to ecosystem processes (IPCC 2007). Numerous studies have determined the relationship between NDVI, an index that measures red and nearinfrared surface reflectance, and vegetation phenology, productivity, and protein content (Homer et al. 2004, IPCC 2007, Maynard et al. 2006). Because of this relationship, NDVI has been used to study wildlife population dynamics and migration patterns (IPCC 2007).

While NDVI is gaining popularity in ecology, little attention has been given to the known limitations of NDVI. Because the scale of satellitederived NDVI is intended to provide complete spatial coverage over single-pixel accuracy, small-scale NDVI assessments needed for wildlife research are often subject to error (Homer et al. 2004). NDVI is known to be affected by dry biomass, high variability in vegetation within pixel, atmospheric contamination, high soil exposure, and high biomass (Homer et al. 2004). Despite the popularity, no consensus has been made about where and when NDVI measures are accurate or limited in the GYE. For decision makers to be confident in the utility of NDVI in estimating the effects of climate and land use change on vegetation and elk population dynamics, validation of the relationship between NDVI and vegetation biomass, phenology, and forage quality is needed.

Building upon research done by Piekielek (2012) using NDVI to determine biophysical predictors of grassland phenology, this study will use field data to validate the accuracy of NDVI estimates of grassland phenology, biomass, and forage quality in migratory elk summer range in the Upper Yellowstone River Basin of the GYE. Piekielek's (2012) primary findings were that "seasonal variation in solar radiation, water availability, evaporative demand and temperature explain much of the variation in the timing of phenology" (Keatley and Hudson 2010). The goal of this research is to combine Piekielek's (2012) findings and the results from this research to provide comprehensive information on the utility of NDVI in predicting the effects of climate and land use change on vegetation metrics in the Upper Yellowstone River Basin. To achieve this goal, this study will validate the spatial and temporal accuracy of satellite-derived NDVI estimates of grassland phenology, biomass, and forage quality throughout the summer growing season in elk migratory ranges in the Upper Yellowstone River Basin.

\section{$\downarrow \quad$ STUDY AREA}

Study Area The study area consists of grasslands, exurban development, and irrigated agriculture in the southern section of the Yellowstone River Basin and grassland meadows in the northern section of Yellowstone National Park.

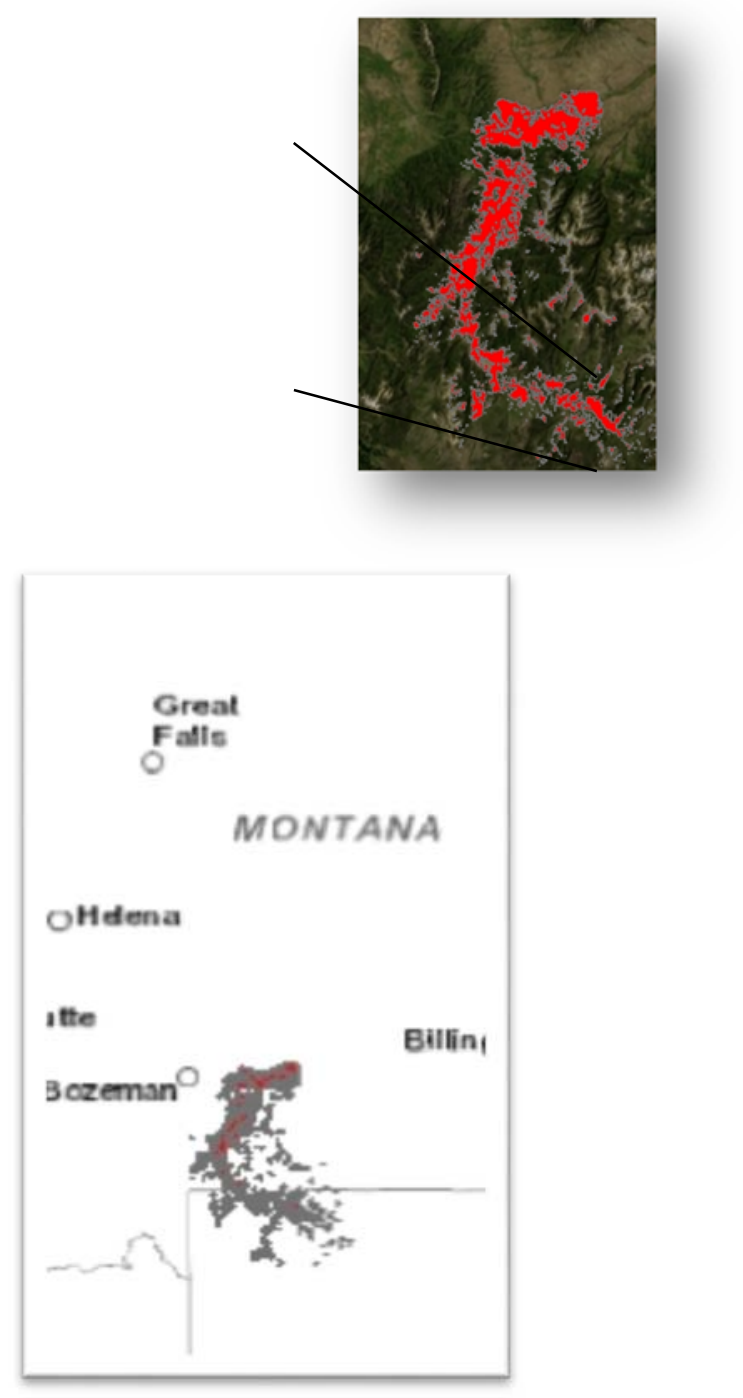

Figure 1: Upper Yellowstone River Basin Study Area Study plot selection.

All $250 \mathrm{~m}^{2}$ MODIS satellite grassland pixels were identified by Piekielek (2012) across the study area using vector-delineated habitat types from Despain (1990) and from National Land Cover Datasets. Snow-off date and maximum annual NDVI (time during the growing season when biomass is maximized) analysis from 2001-2009 by Piekielek (2012) were used to categorize each pixel as early, mid, or late max NDVI phenology categories. Using Montana cadastral data, aerial images, and Piekielek's 
(2012) NDVI analysis, pixels were categorized as private/non-irrigated, private/irrigated, or public/nonirrigated land uses. Three pixels were selected in each land use and phenology category class.

Field data Within each $250 \mathrm{~m}^{2}$ pixel, ten 0.5 $\mathrm{m}^{2}$ quadrats were clipped to ground level every 16 days from April to September for the growing seasons. Above-ground dry biomass, chlorophyll concentration, crude protein and in vitro dry matter digestibility were estimated for each quadrat sample. To explore the relevance of the clippings and NDVI to elk, fresh elk fecal samples were collected within each quadrat when available to compare elk fecal sample phenology and forage quality to the grass clippings and NDVI.

Satellite-derived NDVI MOD13Q1 16-day $250 \mathrm{~m}^{2} \mathrm{NDVI}$ images for the ten sample periods were downloaded from the USGS Land Access Distributed Active Archive. Pixels were reprojected, assessed for quality, and rescaled to fit within the -1-1 NDVI range.

\section{$\uparrow \quad$ PRELIMINARY RESULTS}

Field clippings to estimate biomass, phenology, and forage quality were acquired for 144 pixels throughout the summer growing season of 2013. NDVI values for each pixel were acquired for each time period. Crude protein and in vitro dry matter digestibility tests for the quadrat clippings are still in progress. Preliminary results suggest biomass in the private irrigated land use was greater than both private non-irrigated and public non-irrigated land uses (Figure 2). Biomass was shown to increase at a higher rate in late and early plots than it did in mid phenology plots (Figure 3). Preliminary results suggest that the relationship between NDVI and above ground biomass varied by land use and phenology category (Figures 4 and 5).

Research Progress An additional summer of fieldwork will be completed during the 2014 growing season. After the two field seasons, 320 field pixel estimates of biomass, chlorophyll concentration, crude protein, and in vitro dry matter digestibility will be used to determine the accuracy of NDVI estimates of biomass, phenology, and forage quality.

Management implications Results from this study will provide information to managers, researchers, and conservation organizations on the accuracy of remote sensing NDVI in estimates of grassland biomass, phenology, and forage quality in elk migratory ranges in the Upper Yellowstone River
Basin. Results will be useful for understanding and planning for the potential effects of climate change and human land use on elk forage in the GYE.

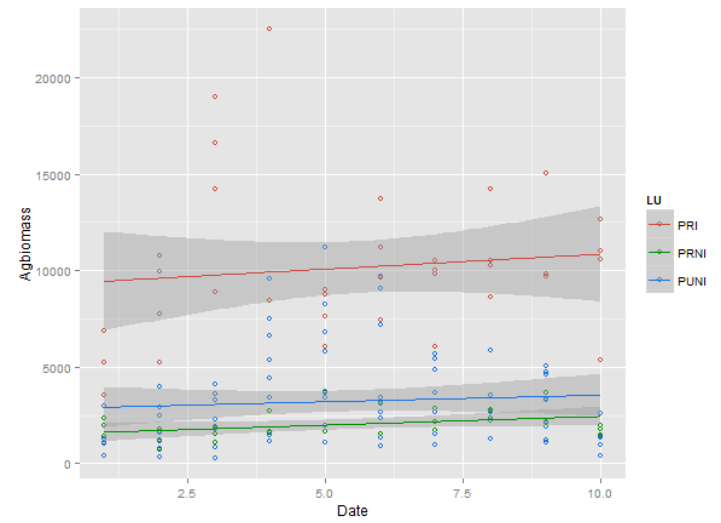

Figure 2. Above ground biomass by date for private irrigated (red), private non-irrigated (green), and public non-irrigated (blue) land use categories.

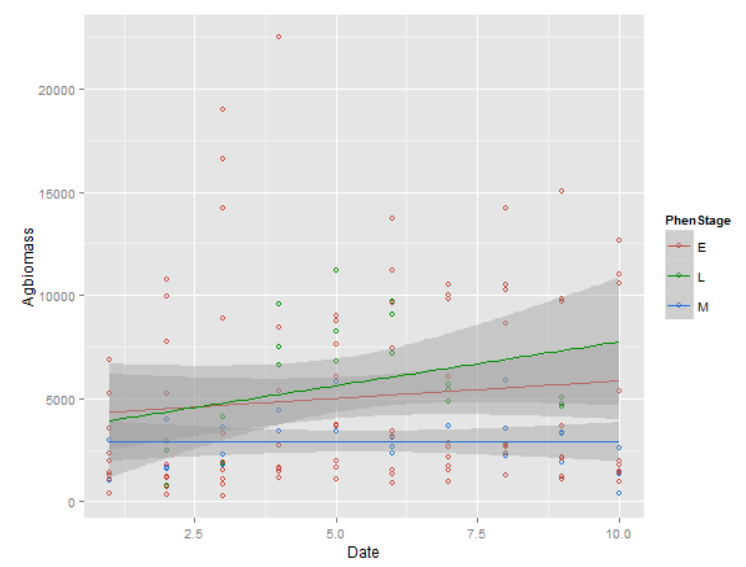

Figure 3. Above ground biomass by date for early (red), mid (blue) and late (green) phenology categories.

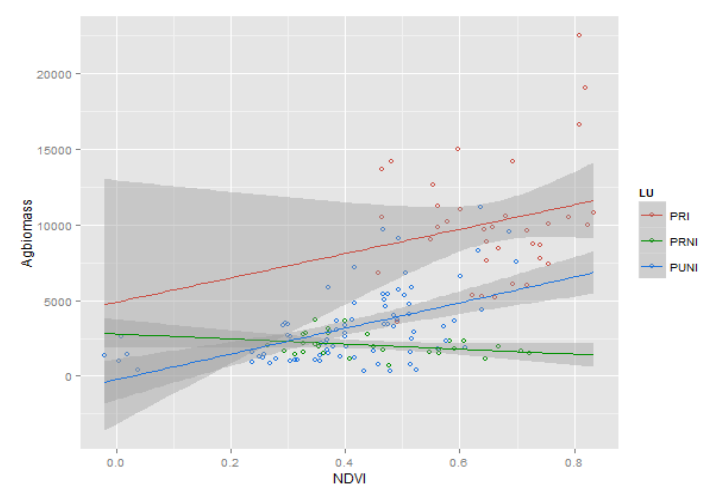

Figure 4. Biomass and NDVI for private irrigated (red), private non-irrigated (green), and public non-irrigated land uses. 


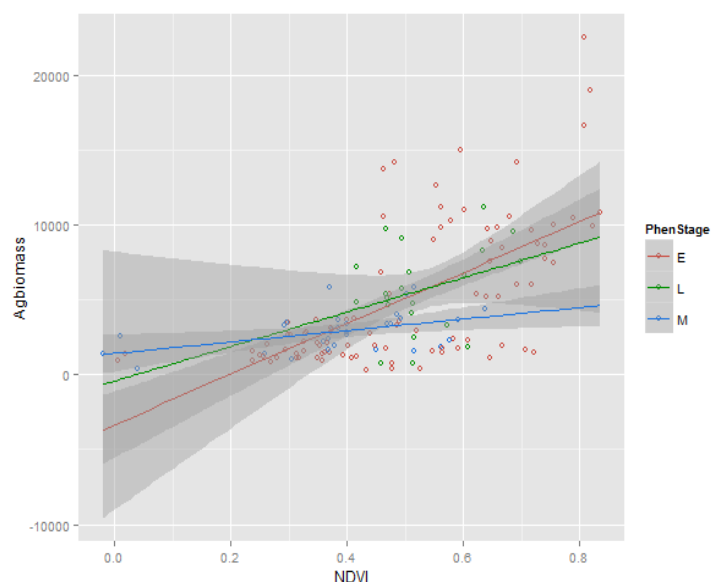

Figure 5. Biomass and NDVI for early (red), mid (blue), and late (green) phenology categories.

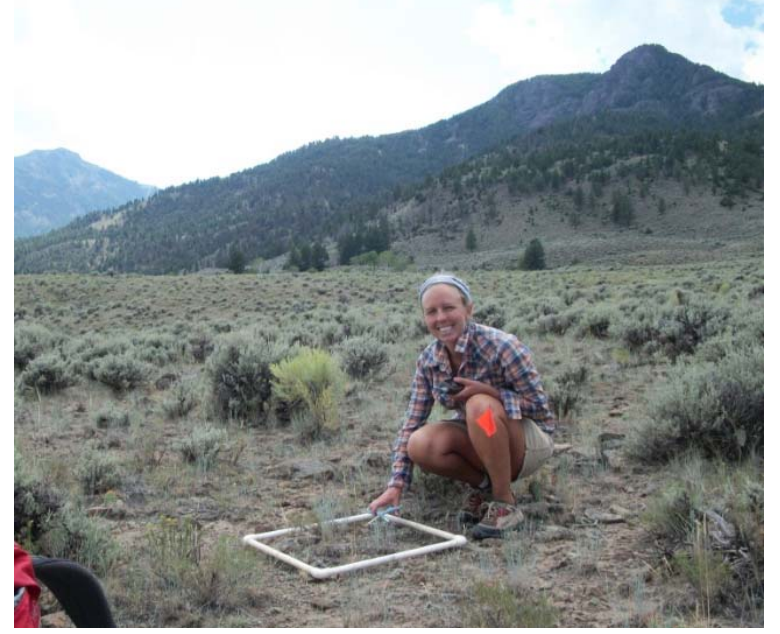

\section{LITERATURE CITED}

Chapin III, F. S., and G. R. Shaver. 1996. Physiological and growth responses of arctic plants to a field experiment simulating climatic change. Ecology 77: 822-840.
Despain, D. G. 1990. Yellowstone vegetation. Robert Rinehart, Boulder, Colorado, USA.

Friedl, M. A., J. Michaelsen, F. W. Davis, H. Walker, and D. S. Schimel. 1994. Estimating grassland biomass and leaf area index using ground and satellite data. International Journal of Remote Sensing 15: 1401-1420.

Harris, G., S. Thirgood, J. G. C. Hopcraft, J. P. G. M. Cromsigt, and J. Berger. 2009. Global decline in aggregated migrations of large terrestrial mammals. Endangered Species Research. 7: 55-76.

Homer, C., L. C. Huang, L. Yang, B. Wylie, and M. Coan. 2004. Development of a 2001 national land-cover database for the United States. Photogrammetric Engineering and Remote Sensing 70: 829-840.

Inouye, D. W. 2008. Effects of climate change on phenology, frost damage, and floral abundance of montane wildflowers. Ecology 89: 353-362.

IPCC (Intergovernmental Panel on Climate Change). 2007. Climate Change 2007: Synthesis Report. Fourth Assessment Report of the Intergovernmental Panel on Climate Change.

Keatley, M. R., and I. L. Hudson. 2010. Phenological research. Pages 1-22, In: I. L. Hudson and M. R. Keatley (eds), Dordrecht.

Maynard C. L., R. Lawrence, G. Nielson, and G. Decker. 2006. GIScience and Remote Sensing 43: 1-14.

Middleton, A. D., M. J. Kauffman, D. E. McWhirter, E. Douglas, J. G. Cook, and R. C. Nelson. 2013. Animal migration amid shifting patterns of phenology and predation: Lessons from a Yellowstone elk herd. Ecology 94: $1245-1256$.

Piekielek, N. B. 2012. Ph.D Thesis. Montana State University, USA. 